\title{
A Quantum Theory of Money and Value
}

David Orrell, Systems Forecasting, Toronto, Canada

dorrell@systemsforecasting.com

\begin{abstract}
The answer to the question 'what is money?' has changed throughout history. During the Gold Standard era, money was seen as gold or silver (the theory known as bullionism). In the early $20^{\text {th }}$ century, the alternative theory known as chartalism proposed that money was a token chosen by the state for payment of taxes. Today, many economists take an agnostic line, and argue that money is best defined in terms of its function, e.g. as a neutral medium of exchange. This paper argues that none of these approaches adequately describes the nature of money, and proposes a new theory, inspired by nonNewtonian physics, which takes into account the dualistic real/virtual properties and complex nature of money. The theory is applied to the example of the emergence of cybercurrencies.
\end{abstract}

Keywords: money, history, cybercurrencies, quantum theory

\section{Introduction}

According to the definition used by most economists, money is anything that serves as a medium of exchange, a store of value, and a unit of account (Ragan and Lipsey, 2011, p. 609). But what special quality is it that gives money these properties? In other words, what makes money, money?

Answers to the question are tied up with ideas about value, and exist over a spectrum, but have typically fallen into one of three camps. The first, known as metallism or bullionism, holds that the special ingredient is precious metal. Money should ideally be made of the stuff, or at least be backed by it. The second camp is chartalism (from the Latin charta for a record) which holds that coins and other money objects are just tokens, that the state agrees to accept as currency (Knapp, 1924, p. 32). In this view, money is backed by the government, which issues it and guarantees that it is accepted for things like payment of taxes. Finally, there is the dominant, hands-off school of thought, which most mainstream economists would agree with, which says that money has no unique or special qualities, but instead is defined by its roles, e.g. a medium of exchange (Samuelson and Nordhaus, 2001, p. 511).

This last view is consistent with the idea that coin money emerged as an improved system of barter. The theory goes back to Aristotle, was elaborated on by economists including Smith (1776), Jevons (1875), and Menger (1892) and still appears in modern textbooks (Ragan and Lipsey, 2011, pp. 672-3). This idea that the economy is best seen as a giant barter system, with money being nothing more than a 'lubricant in exchange', has also influenced the models used by economists (Harper, 1957). A major criticism of the Dynamic Stochastic General Equilibrium models favoured by policy makers, for example, is that they 
do not include the financial sector. ${ }^{1}$ One of the main insights of chartalists was that money existed before the invention of coins, in the form of ancient credit systems, so credit plays a more important role in their theory.

Bullionists and chartalists therefore emphasise a different aspect of money - the inherent value or the authorising stamp - while most economists treat it as an inert chip. But these theories do not adequately describe the complex properties of money. One problem is that they have little to say about the most obvious (if apparently trivial) aspect of money, which is the fact that it is based on number. In bullionism, the role of number is subsumed into the weighing of metal, in chartalism it appears as a unit of value, in mainstream economics it is summarised by the idea of a unit of account - but the idea that we can attach numbers to value in the first place is taken for granted. As discussed below, numbers have properties which are inconsistent with the real world, which is one of the reasons for money's confounding behaviour.

Traditional theories also see money as being inherently stable and inert (rather like gold, which is an inert metal) while in fact it is a powerfully psychoactive substance, which resonates in strong but unpredictable ways with human psychology. ${ }^{2}$ And far from being stable, its nature and our relationship with it have changed radically throughout history, ranging from the detailed accounting systems of ancient Mesopotamia, in which debts were carefully recorded on clay tablets; to the gold-lust of Spanish conquistadors after their discovery of the New World and its copious supplies of precious metal; to the fintech firms producing the latest payment system.

Another problem is that these approaches don't apply well to cybercurrencies. As Georg Friedrich Knapp wrote in his 1905 book, The State Theory of Money, 'the metallists fail to explain currency systems that have no metal. The chartalist has no trouble in explaining them; they are the touchstone of his theory' (Knapp, 1924, pp. 38-39). But both these schools, along with many economists, have trouble with something like bitcoins, which are not made of metal, are not much use for paying taxes, and are not sanctioned by any powerful authority. As Alan Greenspan said: 'I do not understand where the backing of Bitcoin is coming from. There is no fundamental issue of capabilities of repaying it in anything which is universally acceptable, which is either intrinsic value of the currency or the credit or trust of the individual who is issuing the money, whether it's a government or an individual' (Kearns, 2013). Nonetheless, cybercurrencies have proved their metal - you can buy things with them. So maybe the problem is not with cybercurrencies, but with our theories of money.

\section{Number Versus Reality}

Is money best seen as a commodity, or as an idea? Is it real, or virtual? This question goes to the heart of money, and to the debate over what counts as currency.

It is often pointed out, especially by those sympathetic to the chartalist school, that money is not actually a 'thing' but a kind of abstract credit system, and that it is a distraction to focus on material objects such as coins or notes. Alfred Mitchell-Innes wrote in 1914 that, 'The eye has never seen, nor the hand touched a dollar,' in the same way that it hasn't touched a square inch (Innes, 1914, p. 155). However, we first need to distinguish between

\footnotetext{
${ }^{1}$ As former Deputy Governor of the Bank of Canada William White points out, 'An important practical aspect of [DSGE] models is that they make no reference to money or credit, and they have no financial sector' (White, 2013, p. 84).

${ }^{2}$ As Stanford University neuroscientist, Brian Knutson, noted of his experiments: 'Nothing had an effect on people like money - not naked bodies, not corpses. It got people riled up. Like food provides motivation for dogs, money provides it for people' (Levy, 2006, p. 38).
} 
money, and its units. For example, while economics textbooks may routinely state that money serves as 'a unit of account', this is like saying that length serves as a unit of measurement. What they really mean is that monetary units, such as dollars, serve as units of account, which is not the same thing as money itself. We can't pay each other with units.

So the question then becomes, what are these units measuring? Economists have usually answered this, when pressed, by saying that it measures some quantity such as 'labour' (classical economics - see Smith, The Wealth of Nations) or 'utility' (neoclassical economics - see Jevons, 1957). But another approach is to say that it measures - money. After all, when we say that electrons have a fixed electrical charge equal to -e (negative one elementary charge) we don't necessarily try to parse 'electrical charge' down to some finer description. In the same way, we can treat 'money' as a fundamental quantity. Monetary value is a measure of money content in currency units, where here we use 'value' in its quantitative sense, as in a value provided by an instrument reading, and 'money content' is a quantity of money.

In this picture, money is therefore seen as a conserved, transferable stuff, or quantity, like electric charge. But just as in physics it is sometimes easier to understand the concept of electric current in terms of electrons, or light in terms of photons, so we can analyse currency in terms of the actual things which are exchanged in transactions - such as coins, or notes, or money transfers of any kind.

Here we bump into another, apparently trivial but actually rather revealing, linguistic problem. Something like an electronic transfer does not resemble the classic notion of a selfcontained thing, so it might seem inappropriate to describe it as a sort of object being passed from one person or place to another. But this is to misunderstand the nature of objects. The main insight of quantum physics was that matter is composed, not of independent, billiard ball-like atoms, but of entities which behave in some ways as waves, and in other ways as particles. A beam of light, for example, is an electromagnetic wave, but it is also a stream of particles known as photons. The (very real) electromagnetic force which holds objects together is transmitted through the exchange of so-called virtual photons. At a quantum level, matter is fundamentally dualistic: neither the particle nor the wave description is complete by itself. The same can be said of money objects, which bind the properties of numbers and things, the virtual to the real.

Consider, for example, a U.S. dollar bill. On the one hand, it is a physical object which can be owned, traded and above all valued. On the other hand, it represents ' 1 ', which is why it is emblazoned (in 15 places) with that number. And numbers and things are as different as waves and particles. Numbers live in the abstract, virtual world of mathematics, while things live in the real world - and it is the tension between its two sides which give money its powerful but often paradoxical nature. Numbers are exact (even where they represent exact probabilities) while qualities, such as perceived value, depend on the person and the context. Numbers can grow without limits, while natural processes tend to be bounded (being on the wrong side of compound interest has historically been a major reason for people falling into slavery or peonage). Numbers are universal, while objects can be owned, or become scarce. Numbers are hard and fixed, like the particle aspect of matter. Concepts or judgements such as worth or value are fuzzy, like the wave aspect of matter.

The trade of money objects for goods or labour in a market means that those things attain a numerical value as well, namely the price, by contagion, just as the atoms in iron spontaneously align in a magnetic field. Market prices are therefore an emergent property of the system, in the sense that they emerge from the use of money objects. For example, coin money was used in ancient Greece and then Rome as a means for paying and supplying the troops. A Roman soldier's base pay of a denarius per day, coupled with the requirement for 
suppliers to pay fixed taxes, would imply certain approximate price bounds for food, shelter, etc., and these prices would in turn propagate through to any goods that were traded - but ultimately market prices emerged from the use of the coins.

The central concept of money is, therefore, that it is a means to attach exact, timeless numbers to the fuzzy and transient concept of real-world value. The point of doing this is to facilitate certain transactions (e.g. tax payment, exchange, settling of scores, rewards, motivating people) by shifting them to a mathematical space, with its addition, subtraction, and compound interest. While markets assign prices to all kinds of things, money objects are unique in that their value is designed to be objectively fixed and stable. For other goods, their values are indeterminate until the moment they are exchanged for money (just as, according to quantum mechanics, the position or momentum of a particle is fundamentally undetermined until it is measured, at which point it 'chooses' a value). This special status makes money objects desirable in themselves. It is often said that money is just a medium of exchange so need have no value itself; but by attaching numbers to money objects, in a kind of alchemy, we make them valuable. If a society decides that cattle must be used for payments, then cows suddenly become more precious - one cause of overgrazing (Davies, 2002, p. 44). A stack of hundred-dollar bills may only be paper, but it can evoke as much desire as a bar of gold. The distinction between intrinsic and external value, between real and virtual, is blurred.

\section{A Quantum of Money}

Because concepts such as value and authority are socially negotiated, it is not always clear cut whether something should be considered a money object or not. For example, a cheque is an instruction to debit one account and credit another with a certain amount, but its value may be in the eye of the beholder. As one bank writes: 'The reason we have a hold funds policy is that a cheque is not the same as cash - it is a promise to pay by one party to another party. If the first party doesn't have sufficient funds in their account at another financial institution, or if the cheque is fraudulent, that other financial institution can refuse to pay the item and return it unpaid to us. ${ }^{3}$ In this case we would define the money object to be the amount that is actually transferred virtually through the banking system when the cheque is cashed. However if the cheque is endorsed and is itself exchanged between people and accepted as payment, then it becomes a kind of quasi-money object in its own right, with the difference that it is backed less by the state than by the credit of the writer, with the spread between these reflected in a possible discount rate. Banknotes got started in a similar way, but they only fully became money when they were guaranteed by a central bank.

Perhaps the best way to measure the 'moneyness' of an object - its ability to hold money - is to ask how well its market price corresponds to its designated numerical value, and how well equivalence is maintained. In general, this will depend on the authority of the issuer, which varies both geographically and with time. An example is the case where the value of a coin equals its stamp value in the region where it is issued, but elsewhere reflects its metal content; or where a substandard coin trades for less than its face value. This price equivalence also depends on the existence of markets which will accept the object as payment. Private moneys, such as the medieval bills of exchange, are limited not by region but to a circle of users who accept them in exchange.

Money could, in principle, emerge naturally from markets without top-down design or intervention, but the evidence shows that it is better described as a planned social technology. Instead of money emerging from markets, it is historically more accurate to say

\footnotetext{
${ }^{3}$ See https://www.tdcanadatrust.com/document/PDF/520866.pdf
} 
that money-based commercial markets emerged from money, after some pump priming from the state. ${ }^{4}$ Money's behaviour depends on its design and its context, and is shaped and controlled by a variety of forces, such as social customs, power structures, financial institutions, market regulations, physical and intellectual property rights, and so on, but its distinguishing, if rarely-mentioned feature, is its connection to number.

Rather than defining money in terms of its roles as a means of exchange, a store of wealth, an accounting device, a signifier of debt, a measure of labour or utility, a symbol for something else, or insisting that it can be made only from metal (bullionism) or through government edict (chartalism) or that is not fundamentally different from other goods and is really nothing special (mainstream economics), it makes more sense to see money as a quantity in its own right whose roles emerge, deliberately or not, from its use in society. Money is useful for accounting because it is based on number, and has well-defined units. Its roles as store of value and means of exchange are conflated: it is a store of value because money objects are designed to be exchangeable for other things in the economy; it is exchangeable because it is seen as a store of value. The question of real-world value is highly subjective, but the numerical value of money is precisely defined, and this is both the central dichotomy at its heart, and the delicate balancing act which keeps it aloft.

The word 'quantum' has been applied to all kinds of things outside physics and is often misused to evoke a vague sense of spooky, non-mechanistic behavior. The phrase is especially problematic in economics, which has often been accused of suffering from physics envy; and one always needs to be careful about importing analogies from the hard sciences to social sciences (though it is ironic that many theories in economics seem to be explicitly based on Newtonian or Victorian mechanics, without causing too much controversy, while insights from slightly more recent areas of physics tend to be viewed as bordering on the mystical (Orrell, 2012, pp. 109-114)). However the use of the term, and more generally the comparison with non-Newtonian physics, is constructive here for the following reasons:

1. Money is seen as a fundamental quantity (from the Latin quantum).

2. Money objects contain a fixed amount of monetary value, in the same way that an electron contains a fixed amount of charge.

3. Money objects bind the virtual to the real, and abstract number to the fuzzy idea of value, in a way similar to the particle/wave duality in quantum physics.

4. Just as the properties of a substance such as water emerge from the quantum interactions of molecules, so prices emerge from the use of money objects.

5. Money serves as a means to quantify value, in the sense of reducing it to a mathematical quantity - but as in quantum measurement, the process is approximate.

By attaching numbers to our idea of value, in an attempt to quantify it, the money system binds together two very different things, and it is this fusion which gives rise to its complex behaviour. Money objects are our contribution to the quantum universe; and as with quantum physics, the problems in interpretation seem to appear when we try to reduce a system to exact numbers. Perhaps the greatest cause of confusion is that, by attaching numbers to value, money appears to be directly measuring value, which isn't quite the same thing: in general there is no simple, direct relationship between prices and value.

The inherently dualistic nature of money is reflected in its history, which, as David Graeber describes, involves an 'alternation between periods of virtual and metal money' (Graeber, 2011, p. 214). During a virtual phase, money is seen primarily as a score in a

\footnotetext{
${ }^{4}$ Historian Michael Crawford calls the development of markets an 'accidental consequence of the coinage (Crawford, 1970)'.
} 
ledger, while in a physical phase, money is seen primarily as material wealth; however, the two sides cannot be separated, so money always retains the essential characteristics of each. These reversals are written like strata in the historical record, and each layer shows money in a different aspect. Early agrarian empires were dominated by virtual credit, where the value of a clay tablet lay in the inscription, and not so much in the clay. The Axial Age (800 BC to 600 $\mathrm{AD}$ ) saw the widespread adoption of coinage made from precious metals. The Middle Ages, which lasted for almost the next 1,000 years, saw a swing back towards virtual credit, with a shortage of precious metals and the invention of banking instruments such as bills of exchange. The massive influx of gold and silver from the New World in the mid-16 ${ }^{\text {th }}$ century began the metal-money era that led eventually to the international Gold Standard. Since the Nixon Shock of 1971, when fiat currencies decoupled completely from gold, we have been in a virtual age, exemplified by the arrival of cybercurrencies such as bitcoin.

Viewed this way, the opposing theories of bullionism and chartalism can be seen as each emphasising a different side of money. The situation resembles the long debate over the properties of light, with one school claiming it was made of particles, the other it was made of waves, until the question was finally resolved by saying it was both at the same time, with the different aspects presenting themselves in different contexts.

\section{Emerging Markets}

Implicit to traditional theories is the idea that money has to be backed by some pre-existing quantity, be it real (e.g. metal) or virtual (e.g. the law of the state). It, therefore, inherits its value passively from outside. But from a quantum perspective, rather than money being backed by something of monetary value, it is the other way round - market value comes from the use of money. This has implications for the way we interpret phenomena such as cybercurrencies, and, in particular, helps to explain their ability to boot themselves up from nothing more than a set of rules and an internet connection.

As mentioned above, money objects are unique in that they have a fixed, defined monetary value, which makes them desirable in themselves - so the more something looks like money, the more valuable its numbers become, in a self-reinforcing dynamic. And just as market prices emerge from the use of money objects, so the money system expands with its markets. A cybercurrency is supported not by metal or the state, but by something much more distributed and amorphous - its network of users. A property of networks is that their power expands rapidly with size (sometimes called the fax effect, since fax machines were of little use until enough people had them). The value of a cybercurrency - and the trust it embodies - therefore grows in the same way with the size of the network of users, so can initially be near-zero. Note that the two opposite sides of money, which represent positive credit and negative debt, in a sense cancel each other out, so a kind of conservation principle is observed, as when matter/antimatter pair particles are created from the quantum void. It is therefore not necessary to begin with an external debt or a source of value, because the two can expand together. Numbers which were just numbers, can suddenly become worth a great deal.

When Satoshi Nakomoto mined the first bitcoins in January 2009, he (if it is a he) had to give them away to get people interested. They had numbers, and a unit of account, but no value. In October of that year, users set up a web site quoting a price which corresponded to the cost of electricity required to mint a coin. This worked out at the time to about 0.0008 dollars per bitcoin, so a thousand bitcoins was worth about 80 cents. Once a price was available, people began to trade, but it remained a game - until May 2010 when a software 
engineer managed to buy two pizzas for 10,000 BTC, by posting a request on the bitcoin forum. Someone accepted the bitcoins and ordered the pizzas using a credit card.

Bitcoins were becoming things, and their numbers were attaching themselves to other things. Within the space of months, all kinds of things could be bought with bitcoin (not all of them legal, which was why the FBI closed down the Silk Road website in 2013). Today, the price paid for each of those pizzas works out to about a million dollars. Bitcoin, therefore, began with no backing at all, unless you count the cost of electricity (more on this below), but its usefulness grew with the network as more people accepted the coins. And in the end, a currency doesn't need to be backed - it needs to be used.

One reason cybercurrencies have met with resistance - from economists such as Alan Greenspan but also the general public - is because they do not conform to our traditional ideas about money and value. According to bullionism, a money object needs to contain a certain amount of metal, whose inherent value is taken as granted. According to chartalism, the value of a money object is specified by an authority, whose power is assumed to exist. When the first bitcoins were mined, they had neither inherent value, nor the power of an authority. Instead the two aspects - the real and the virtual - grew together, reinforcing each other as the number of users expanded. There was no clear transition or a particular date when it was officially established that bitcoin should be accepted as money at a certain exchange or price level; rather a kind of creeping phase transition, where bitcoin began to look less like an interesting experiment and more like money, until a critical mass of users was achieved.

When faced with a new phenomenon, such as bitcoin, that does not fit with preconceived beliefs, the simplest strategy is to deny its existence, for example by saying that it is not real money, or does not have 'real meaning' as the People's Bank of China put it in 2013. But when you can use bitcoin to buy ether to buy a stake in a decentralised autonomous organization (DAO), which can invest in start-up companies, including new blockchain-based schemes, and so on, we have to accept that this cyber-economy deserves to be taken seriously by the economics community. Indeed, it is serving as a kind of monetary petri-dish, allowing us to see how currencies get started and either perish or survive, and also to test out our ideas about money.

The problem then is not with cybercurrencies, but with theories of money which were shaped by previous monetary eras of Gold Standard or state fiat currencies. If fiat currencies are the touchstone of chartalism, as Knapp wrote, then cybercurrencies are the touchstone of the theory presented here, which sees money as a fundamental quantity rather than something dependent on external pre-existing causes, and value as an emergent property of the money system.

Traditional theories may in fact have affected the design of bitcoin, which in many respects seems to have been intended as a virtual version of gold. The future supply of bitcoins is limited to a cap of 21 million; for comparison, the total amount of mined gold in the world is estimated to be about 6 billion ounces. Bitcoin's proof-of-work mining process is also highly energy intensive, much like the mining of gold. In part this is a security feature, because it imposes a cost on attempts to disrupt the blockchain; but it may also reflect the idea that money, to be valuable, needs to be backed by something else - in this case, electricity. Adam Smith, who equated value with labour, would have approved (assuming that the labour of computers counts). However, this does raise the question of whether an alternative approach which simplifies the mining process would be more efficient (for example a proof-of-stake algorithm rewards miners with something like interest payments on their holdings). It will be ironic if the world's leading cybercurrency founders because it is too much like gold. 


\section{Conclusion}

The core idea of the theory presented here is that money objects are entities (taking many different forms) which have an assigned monetary value. Because number and value are fundamentally different, such money objects exhibit dualistic properties. For things other than money objects, the relationship between value and price is something that emerges indirectly from the use of money, so is an emergent property which depends on a wide variety of social factors.

Money objects, with their dual real/virtual nature, have one foot in the abstract world of number and computation, and another in the real world of physical things. Just as forces, such as magnetism, are communicated by exchanging virtual particles, so commercial transactions involve the exchange of money objects, whose dualistic properties - both contradictory and reinforcing - feed into the economy, and are registered as oscillations between real and virtual phases in the 5000-year history of markets. While money occupies a special place in the intersection between the world of real objects and ideas of social value, its dualistic properties are experienced by society as a whole (Orrell and Chlupatý, 2016, pp. 169-175).

One of these properties of money that interests us today is the ability of cybercurrencies to boot themselves out of the ether. The question is not whether such things count as money - they clearly do - but whether they can offer concrete advantages over traditional currencies, and prevail as part of the monetary system. A prerequisite for their widespread adoption is that we shed our outmoded, Newtonian theories about money, which were developed for earlier monetary eras.

This paper has not gone into implications for things like monetary policy, or explored in detail the interesting question of how currencies in general emerge into widespread use. ${ }^{5}$ Describing money systems as a kind of emergent phenomenon might sound a little dismissive, as if there is no point in exploring further the dynamics of their creation or use; but this is far from being the case, as seen again by a comparison with physics. The remarkable and life-supporting qualities of water, for example, are an emergent result of the complex quantum interactions between water molecules. Solid-state physics, whose useful applications include computers, is similarly based on the emergent properties of materials (Laughlin, 2005, p. 80). Exploring how money systems grow or are imposed, and either reach a critical mass or fail, is an equally fascinating area of study. Bitcoin may draw its authority from its network of users, but in a way the same can be said of any form of money; the difference is that conventional currencies get a boost from the state. The recent and ongoing emergence of a diverse ecosystem of cybercurrencies offers economists a unique opportunity to study the process by which currencies come into use, with governments, corporations, and other organisations all playing a role.

As shown by the history of money, debates over the nature of money are not just theoretical questions, but go to the heart of how the economy is managed (as during the Gold Standard). Again, treating money systems as an emergent property may seem to undercut this assertion - after all, the discovery of the quantum properties of water molecules did not affect the way we do plumbing. But money, unlike water, responds to the way we think about it. And by treating money as an inert chip, and omitting it from key economic models, we have blinded ourselves towards its true potential, for improving our lives or for creating chaos. Will new currencies help to rebalance our economic system? Can we design currencies to aim for particular societal outcomes? Does it make sense for private banks to carry out the bulk of money creation by issuing loans, given that money is not a passive accounting system but an

\footnotetext{
${ }^{5}$ This topic is explored in more detail in Orrell and Chlupatý (2016).
} 
active and powerful substance? Only by acknowledging the complex, dualistic, and above all lively nature of money can we fully address such questions, and incorporate money properly into our study of the economy.

\section{Acknowledgements}

The author would like to thank two reviewers, James Culham and Annalisa Rosselli, for their insightful comments at the Economic Thought Open Peer Discussion forum on an earlier draft. These prompted a number of improvements and clarifications in the text.

\section{References}

Crawford, M. H. (1970) 'Money and exchange in the Roman world.' Journal of Roman Studies, 60, pp. 40-48.

Davies, G. (2002) A history of money: from ancient times to the present day. 3rd ed. Cardiff: University of Wales Press.

Graeber, D. (2011) Debt: The First 5000 Years. Brooklyn, NY: Melville House.

Innes, A. M. (1914) 'The Credit Theory of Money'. The Banking Law Journal, 31(Dec/Jan), pp. 151-168.

Harper, F. A. (1957) Why Wages Rise. Irvington-On-Hudson, NY: Foundation for Economic Education.

Jevons, W. S. (1875) Money and the Mechanism of Exchange. New York: D. Appleton and Co.

Jevons, W. S. (1957) The Theory of Political Economy. 5th Edition. New York: Kelley and Millman.

Kearns, J. (2013) 'Greenspan Says Bitcoin a Bubble Without Intrinsic Currency Value.' Bloomberg, 4 December.

Knapp, G. (1924) The State Theory of Money. London and New York: Macmillan and Company.

Levy, A. (2006) 'Mapping the trader's brain.' Bloomberg Markets, 1 February, 15(3), pp. 34-45.

Laughlin, R.B. (2005) A different universe: Reinventing physics from the bottom down. New York: Basic Books.

Menger, K. (1892) 'On the origins of money.' Economic Journal, 2(3), pp. 239-255.

Orrell, D. (2012) Truth or Beauty: Science and the Quest for Order. New Haven, Conn.: Yale University Press.

Orrell, D. and Chlupatý, R. (2016) The Evolution of Money. New York: Columbia University Press.

Samuelson, P. A. and Nordhaus, W. D. (2001) Economics. 17th ed. Boston, MA: McGrawHill.

Smith, A. (1776) An Inquiry into the Nature and Causes of the Wealth of Nations. London: W. Strahan \& T. Cadell. 
Ragan, C. T. and Lipsey, R. G. (2011) Economics. 13th ed. Toronto: Pearson Education Canada.

White, W. R. (2013). 'Is Monetary Policy A Science? The Interaction Of Theory And Practice Over The Last 50 Years.' In M. Balling, \& E. Gnan (eds.), 50 Years of Money and Finance Lessons and Challenges. Vienna: SUERF.

\section{SUGGESTED CITATION:}

Orrell, D. (2016) 'A Quantum Theory of Money and Value.' Economic Thought, 5.2, pp. 19-28.

http://www.worldeconomicsassociation.org/files/journals/economicthought/WEA-ET-5-2-Orrell.pdf 